\title{
Pigsties near dwellings as a potential risk factor for the prevalence of Japanese encephalitis virus in adult in Shanxi, China
}

Xiaojie Ren ${ }^{1 \dagger}$, Shihong $\mathrm{Fu}^{2,3+}$, Peifang Dai ${ }^{4 \dagger}$, Huanyu Wang ${ }^{2,3}$, Yuanyuan $\mathrm{Li}^{1}$, Xiaolong $\mathrm{Li}^{2,3}$, Wenwen $\mathrm{Lei}^{2,3}$, Xiaoyan Gao ${ }^{2,3}$, Ying He $\mathrm{H}^{2,3}$, Zhi Lv $\mathrm{Lv}^{2,3}$, Jingxia Cheng ${ }^{4}$, Guiqin Wang ${ }^{1 *}$ and Guodong Liang ${ }^{2,3^{*}}$

\begin{abstract}
Background: The increasing trend of adult cases of Japanese encephalitis (JE) in China, particularly in northern China, has become an important public health issue. We conducted an epidemiological investigation in the south of Shanxi Province to examine the relationships between mosquitoes, Japanese encephalitis virus (JEV), and adult JE cases.

Methods: Mosquito specimens were collected from the courtyards of farmers' households and pig farms in Shanxi Province. Mosquitoes were pooled, homogenized, and centrifuged. Reverse transcription-polymerase chain reaction (RT-PCR) was used to detect mosquito-borne arbovirus genes in homogenates. Specimens positive for these genes were inoculated into the baby hamster kidney cell line (BHK-21) to isolate virus. Minimum infection rate was calculated and phylogenetic analyses were performed.

Results: A total of 7943 mosquitoes belonging to six species in four genera were collected; Culex tritaeniorhynchus accounted for 73.08\% (5 805/7 943), C. pipiens pallens for 24.75\% (1 966/7 943), and the remaining 3\% (104/ 7943) consisted of Anopheles sinensis, Aedes vexans, Ae. dorsalis, and Armigeres subalbatus. Sixteen pools were positive for JEV based on RT-PCR using JEV pre-membrane gene nested primers. Phylogenetic analyses showed that all JEVs belonged to genotype I; two pools were positive using Getah Virus (GETV) gene primers. In addition, one JEV strain (SXYC1523) was isolated from C. pipiens pallens specimens. These results indicate that the minimum infection rate of JEV in mosquito specimens collected from the courtyards of farmers' households with pigsties was 7.39/1 000; the rate for pig farms was 2.68/1 000; and the rate for farmers' courtyards without pigsties was zero.

Conclusions: The high-prevalence regions of adult JE investigated in this study are still the natural epidemic focus of JEV. Having pigsties near dwellings is a potential risk factor contributing to the prevalence of adult JE. To prevent the occurrence of local adult JE cases, a recommendation was raised that, besides continuing to implement the Expanded Program on Immunization for children, the government should urge local farmers to cease raising pigs in their own courtyards to reduce the probability of infection with JEV.
\end{abstract}

Keywords: Adult Japanese encephalitis, Epidemic disease, Mosquito-borne arbovirus, Japanese encephalitis virus

\footnotetext{
*Correspondence: guiqinwang321@163.com; gdliang@hotmail.com

${ }^{\dagger}$ Equal contributors

'Department of Immunology and Microbiology, Shanxi Medical University,

Taiyuan 030001, China

${ }^{2}$ State Key Laboratory of Infectious Disease Prevention and Control, National Institute for Viral Disease Control and Prevention, Chinese Center for Disease Control and Prevention, Beijing 102206, China

Full list of author information is available at the end of the article
} 


\section{Multilingual abstracts}

Please see Additional file 1 for translations of the abstract into the six official working languages of the United Nations.

\section{Background}

Japanese encephalitis (JE) is a central nervous system disease caused by Japanese encephalitis virus (JEV), which has severe symptoms and a fatality rate of $30 \%$. About $35 \%$ of survivors have permanent neurological or psychiatric sequelae $[1,2]$. JEV is transmitted by mosquitoes, among which Culex tritaeniorhynchus is the most important vector. Pigs and migratory birds are primary amplification hosts [1-3]. JE is mainly epidemic in developing countries in Asia such as China, India, Thailand, Vietnam, Myanmar, Laos, and Indonesia. It is also the most important form of viral encephalitis in these regions $[3,4]$. JE mainly occurs in children up to 14 years old [1-4], but adult cases have been reported in recent years. In 2006, 66 cases of JE were reported with 22 deaths in Shanxi Province, China, among which only 1 patient was 4 years old and more than $86 \%$ were over 30 years old [5]. In recent years, the number of adult cases has exceeded pediatric cases in some endemic areas in India [6]. In addition, 129 cases were reported in South Korea during 2010-2015, among which patients older than 40 years accounted for 61.2\% [7]. Therefore, the epidemic of adult JE in local regions has become a new public health issue.

China has the highest prevalence rates of JE, accounting for nearly $50 \%$ of the total number of cases reported around the world annually [4]. In 2008, China has included JE vaccination in the Expanded Program on Immunization (EPI), and children $\leq 15$ years old in JEendemic areas can be inoculated with JE vaccine at no cost; this has greatly reduced the incidence of JE in children [8-10]. However, the incidence of adult cases in some provinces of China is higher than the national average, and the increased proportion of cases in adults is much higher than that in children [10]. The increase in adult JE cases, particularly in patients over 40 years old, has gradually become the driving factor for the high national incidence of JE from 2004 to 2014 in China. Previous studies have shown that the number of JE cases in the $\leq 15$ years old group decreased by $17 \%$ in 2013 , while that in people $>40$ years old increased by $394.16 \%$ compared to 2012 [10]. There are six high-prevalence provinces for adult JE (Shanxi, Shandong, Henan, Hebei, Shaanxi, and Gansu), all of them located in north of the Yangtze River $\left(30^{\circ} \mathrm{N}-35^{\circ} \mathrm{N}\right.$ and $\left.110^{\circ} \mathrm{E}-130^{\circ} \mathrm{E}\right)$. Spatial cluster analyses have suggested that the distribution of adult cases in the south of Shanxi Province have demonstrated spatial clusters in years with high JE prevalence rates. Thus, the high incidence of adult JE in the southern region of Shanxi Province has become a heavy burden on local public health [10].

A total of 253 JE cases were reported in Shanxi province from 2009 to 2014, among which adult JE cases (over 40 years old) accounted for 83\% (210/253). The adult cases were mainly distributed in Linyi, Yongji, and Wanrong counties, accounting for $35.7 \%$ (75/210) of the total (Fig. 1). Therefore, we conducted an investigation in these three counties to understand the relationships between local mosquito vectors, JEV, and local adult JE cases.

\section{Methods \\ Cells}

The baby hamster kidney cell line (BHK-21) was used for virus isolation. Cells were cultured with Dulbecco's Modified Eagle's Medium (DMEM) (Gibco, Grand Island, NY), 6\% fetal bovine serum (FBS) (Gibco), 1\% $100 \mathrm{U} / \mathrm{ml}$ penicillin and streptomycin (prepared by the Institute of Virology), and maintained at $37{ }^{\circ} \mathrm{C}$ under an atmosphere of $5 \% \mathrm{CO}_{2}[11,12]$.

\section{Mosquito collection}

Previous papers showed that the mosquito density peaked from June to August and August has the highest mosquito density in the study area. The study area is on the east coast of the Yellow River. In summer, it is hot and rainy suitable for mosquito breeding, which is in June to August. Farmers grow wheat, corn, rice, cotton, potato, sorghum, millet, soybean, apple and so on. Vegetation is dominated by deciduous broad-leaf forest. JE cases peaked in June and August in Shanxi Province. So we collected mosquitoes from August 17 to 23, $2015[5,9]$. The three counties are located between $34.8^{\circ} \mathrm{N}$ and $35.4^{\circ} \mathrm{N}, 110.3^{\circ} \mathrm{E}$ and $110.83^{\circ} \mathrm{E}$ (Fig. 1) in the Yellow River basin, which includes a large part of the Yellow River alluvial plain. Therefore, there are abundant rivers and lakes. Mosquito specimens were collected throughout this region, in villages with populations of about 800-1 000 people (200-300 households) per village. The distance between each village was more than $5 \mathrm{~km}$. The investigation sites were divided into three categories, as follows.

1) Courtyards of farmers' households with pigsties: there were not only houses for human habitation, but also pigsties for 5-10 pigs in the courtyard. The pigs were all raised in the courtyards, and there were no large-scale pig farms in these villages.

2) Courtyards of farmers' households without pigsties: all pigs were intensively bred in pig farms $2 \mathrm{~km}$ from the village. Therefore, there were no pigs raised in the farmers' courtyards in these villages. 


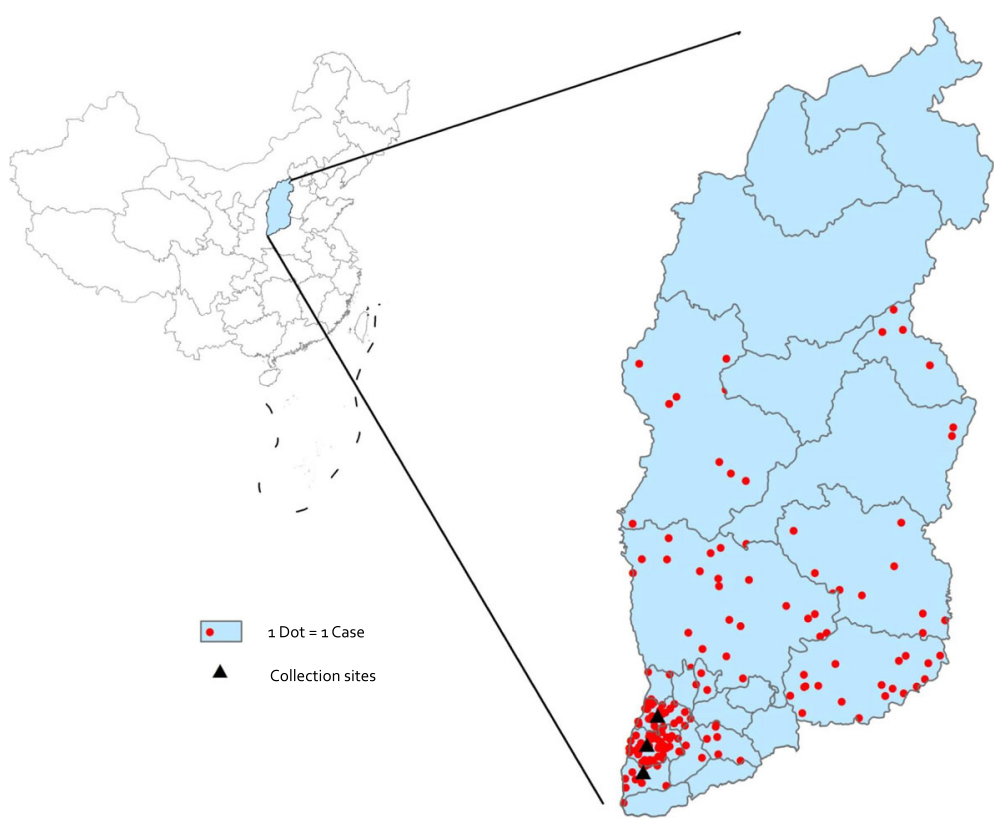

Fig. 1 Geographical distribution of adult JE cases in Shanxi Province from 2009 to 2014, and the collection sites of mosquito specimens in this study. The triangles represent Wanrong, Linyi, and Yongji from top to bottom in the figure, respectively

3) Pig farms: the pig farms with intensive breeding of about 1000 pigs were located $2 \mathrm{~km}$ from the villages. Residents in the village rented them according to the number of pigs they owned. Fulltime personnel were responsible for the daily breeding and management of pigs on the farms.

Mosquitoes were collected with Ultraviolet light traps (Wuhan Lucky Star Environmental Protection Technology Co. Ltd., Hubei, China) and MT-1 $\mathrm{CO}_{2}$ mosquito traps (Beijing Detailong Science and Technology Development Co. Ltd., Beijing, China). The traps were set before sunset at 5:00 PM and mosquitoes were collected from them the following morning at 7:00 AM. The trapped mosquitoes were killed by freezing at $-20{ }^{\circ} \mathrm{C}$ for $30 \mathrm{~min}$. The specimens were placed on ice, and identified under a microscope for morphological classification. Male mosquitoes were excluded. Female mosquitoes were combined into different pools $\leq 120$ specimens according to species, collection site, and collection time. The information was marked and registered. The specimens were stored in liquid nitrogen until they were examined in the laboratory $[11,12]$.

\section{Virus isolation}

Pools of mosquito specimens were homogenized using a Mixer Mill Tissuelyser II (Qiagen, Hilden, Germany) at 25 times per second for 3 min with stainless steel beads $(r=3 \mathrm{~mm})$ in $2 \mathrm{ml}$ sterile plastic tubes containing $1.5 \mathrm{ml}$
Eagle's medium supplemented with $5 \% 100 \mathrm{U} / \mathrm{ml}$ penicillin and streptomycin, $1 \% 30 \mathrm{~g} / \mathrm{L}$ glutamine, and $1 \%$ $75 \mathrm{~g} / \mathrm{L} \mathrm{NaHCO}_{3}$. Then the samples were centrifuged at $13000 \mathrm{rpm}, 4{ }^{\circ} \mathrm{C}$, for $30 \mathrm{~min}$.

Aliquots of $100 \mu \mathrm{l}$ clarified homogenates were inoculated into $5.5 \mathrm{~cm}^{2}$ Nunc tubes (Nunc, Roskilde, Denmark) covered with a BHK cell monolayer containing $100 \mu \mathrm{l}$ Eagle's medium for $1 \mathrm{~h}$ at $37{ }^{\circ} \mathrm{C}$ under an atmosphere of $5 \% \mathrm{CO}_{2}$. Then the medium was replaced with $2 \mathrm{ml}$ fresh medium and the tubes were maintained at $37{ }^{\circ} \mathrm{C}$ under an atmosphere of $5 \% \mathrm{CO}_{2}$. The cytopathic effect $(\mathrm{CPE})$ was examined every $8 \mathrm{~h}$ for 5 days. Control BHK-21 cells were also examined at each stage. At $70 \% \mathrm{CPE}$, the samples were stored at $-80^{\circ} \mathrm{C}$ until identification. Those without a $\mathrm{CPE}$ were blindly passaged for three successive generations in the same way $[11,12]$.

\section{RT-PCR and molecular identification}

RNA was extracted from $140 \mu \mathrm{l}$ aliquots of clarified homogenates or virus culture stocks with a Viral RNA Mini Kit (QIAamp; Qiagen, Valencia, CA) in accordance with the manufacturer's protocol. Then the viral RNA was used as the template to prepare cDNA with random primers (6-mer) (Takara, Otsu, Japan) using Ready-To-Go ${ }^{\mathrm{mm}}$ You-Prime FirstStrand Beads (GE Healthcare, Little Chalfont, Buckinghamshire, UK). The primers used for mosquito-borne virus gene detection are shown in Table 1 [12-15]. In this study, we detected not only JEV genes but also common arboviruses that had been discovered in local mosquito 
Table 1 Primers used for identification in this study ${ }^{a}$

\begin{tabular}{|c|c|c|c|}
\hline Primers & Sequence of primers $\left(5^{\prime}-3^{\prime}\right)$ & Amplify region & Length of product (reference) \\
\hline \multicolumn{4}{|l|}{ Flavivius } \\
\hline FU1 & TACCACATGATGGGAAAGAGAGAGAA & NS5 & $310[11]$ \\
\hline CFD2 & GTGTCCCAGCCGGCGGTGTCATCAGC & & \\
\hline \multicolumn{4}{|l|}{ Alphavirus } \\
\hline $\mathrm{M} 2 \mathrm{~W}$ & YAGAGCDTTTTCGCAYSTRGCHW & NS1 & $434 / 310[11]$ \\
\hline cM3W & ACATRAANKGNGTNGTRTCRAANCCDAYCC & & \\
\hline M2W2 & TGYCCNVTGMDNWSYVCNGARGAYCC & & \\
\hline \multicolumn{4}{|l|}{ Bunyaviruses } \\
\hline BUP & ATGACTGAGTTGGAGTTTGATGTCGC & $\mathrm{S}$ & $251[13]$ \\
\hline BDW & TGTTCCTGTTGCCAGGAAAAT & & \\
\hline \multicolumn{4}{|c|}{ BAV S12 gene primers } \\
\hline BAV-12-854-S & AAATTGATAGYGYTTGCGTAAGAC & $\mathrm{S} 12$ & $850[11]$ \\
\hline BAV-12-B2-R & GTTCTAAATTGGATACGGCGTGC & & \\
\hline \multicolumn{4}{|c|}{ LNV S12 gene primers } \\
\hline LNV12s1 & CACTGGCTCCGGCTGTAGTAACAG & $\mathrm{S} 12$ & $435[14]$ \\
\hline LNV12r1 & CTGTTCGGATCATCTGGAATTTGA & & \\
\hline \multicolumn{4}{|c|}{ GETV 5'UTR and NS1 gene primers } \\
\hline F1 & ATGGCGGACGTGTGACATCAC & 5'UTR,NS1 & $930[15]$ \\
\hline R1 & GTAACCTTCGCATGACACCACC & & \\
\hline \multicolumn{4}{|c|}{ JEV C/PrM gene primers } \\
\hline$J E-251 F$ & CGTTCTTCAAGTTTACAGCATTAGC & C/PrM & $674 / 492[5]$ \\
\hline JE-925R & CCYRTGTTYCTGCCAAGCATCCAMCC & & \\
\hline JE-743R & CGYTTGGAATGYCTRGTCCG & & \\
\hline
\end{tabular}

F, Forward primer; R, Reverse primer; $M, C / A ; W, A / T ; Y, C / T ; K, G / T ; R, G / A ; V, G / A / C ; D, T / A / G ; B A V$, Bannan virus; LNV, Liaoning virus; GETV, Getach virus; JEV, Japanese encephalitis virus

${ }^{a}$ The primers used to amplify the complete open reading frame (ORF) nucleotide sequence and envelope gene of the viral genomic RNA were all from a previous study [23]

specimens. PCR was performed with GoTaq $^{\circledR}$ Green Master Mix, 2× (Promega, Madison, WI) using a Mastercycler (Eppendorf, Hamburg, Germany) as follows: initial denaturation at $95{ }^{\circ} \mathrm{C}$ for $4 \mathrm{~min}$ followed by 35 cycles of denaturation at $95{ }^{\circ} \mathrm{C}$ for $30 \mathrm{~s}$, annealing at $55{ }^{\circ} \mathrm{C}$ for $30 \mathrm{~s}$, and extension at $72{ }^{\circ} \mathrm{C}$ for $1 \mathrm{~min}$, with a final extension at $72{ }^{\circ} \mathrm{C}$ for $10 \mathrm{~min}$. Amplified products were detected by $1 \%$ agarose gel electrophoresis and sequenced. BLAST searches of the nucleotide sequences obtained were conducted against GenBank to identify the types of virus genes in the specimens [11, 12].

\section{Minimum infection rate}

Minimum infection rate (MIR) was calculated as the (number of pools positive for JEV/total number of specimens tested) $\times 1000$, assuming that every positive pool contained only one infected mosquito. This was calculated for each mosquito species and each mosquito collection site during the study [16].

\section{Phylogenetic analysis}

Seqman software (DNAStar, Madison, WI) was used for sequence splicing and quality analysis of the original nucleotide sequence. Additional JEV sequences were downloaded from GenBank. The JEV strains used in this study with source and region of isolation are listed in Table 2. BioEdit software (version 7.0.5.3; Thomas) was used for multiple alignment by ClustalW.MegAlin software (DNAStar) was used to convert nucleotide sequences into amino acid sequences and to separately compare nucleotide and amino acid sequence identities.

Phylogenetic analyses were performed by the neighbor-joining (NJ) method using Mega software with 1000 bootstrap replicates. To generate rooted trees, Murray Valley encephalitis virus (MVE) was used as an outgroup in the JEV phylogenetic analysis $[11,12]$.

\section{Results}

Distribution of mosquitoes

A total of 7943 mosquitoes were collected from Linyi, Yongji, and Wangrong counties, Shanxi Province, from 
Table 2 Strains of Japanese encephalitis virus used in this study

\begin{tabular}{|c|c|c|c|c|c|c|}
\hline \multirow[t]{2}{*}{ Strain } & \multirow[t]{2}{*}{ Genotype } & \multirow[t]{2}{*}{ Year } & \multirow{2}{*}{$\begin{array}{l}\text { Country and } \\
\text { region }\end{array}$} & \multirow[t]{2}{*}{ Source } & \multicolumn{2}{|c|}{ GenBank accession No. } \\
\hline & & & & & E gene & Complete gene \\
\hline SXYC1523* & I & 2015 & Shanxi,China & Culex pipiens & KY078829 & KY078829 \\
\hline SXYC1546* & 1 & 2015 & Shanxi,China & C. tritaeniorhynchus & KY078827 & \\
\hline SXYC1548* & I & 2015 & Shanxi,China & C. tritaeniorhynchus & KY078828 & \\
\hline Ishikawa & । & 1994 & Ishikawa, Japan & Swine mononuclear cells & AB051292 & AB051292 \\
\hline $\mathrm{JEV} / \mathrm{sw} / \mathrm{Mie} / 40 / 2004$ & I & 2004 & Japan & Pig serum & AB241118 & AB241118 \\
\hline 12-YJ033 & I & 2012 & Shanxi,China & C. tritaeniorhynchus & KP216590 & \\
\hline SX09S-01 & । & 2008 & Shanxi,China & Pig brain & HQ893545 & HQ893545 \\
\hline 12-LY039 & । & 2012 & Shanxi,China & C. pipiens & KP216598 & \\
\hline 12-YJ022 & I & 2012 & Shanxi,China & C. tritaeniorhynchus & KP216587 & \\
\hline XJ69 & 1 & 2007 & China & C. pipiens pallens & EU880214 & EU880214 \\
\hline SH03-130 & । & 2003 & Shanghai, China & C. tritaeniorhynchus & DQ404104 & \\
\hline KV1899 & । & 1999 & Korea & Pig serum & AY316157 & AY316357 \\
\hline YN79-Bao83 & । & 1979 & Yunan, China & C. tritaeniorhynchus & DQ404128 & \\
\hline YN-Xiang JE & 1 & IU & Yunan, China & Human blood & DQ404135 & \\
\hline LN02-102 & I & 2002 & Liaoning, China & C. modestus & DQ404085 & \\
\hline SH03-105 & । & 2003 & Shanghai, China & C. tritaeniorhynchus & DQ404097 & \\
\hline HN06-21 & । & 2006 & Henan, China & Culex & JN381830 & \\
\hline HN06-26 & 1 & 2006 & Henan, China & Culex & JN381837 & \\
\hline sC04-12 & I & 2004 & Sichuan, China & Culex & DQ404090 & \\
\hline GZ56 & । & 2008 & Guizhou, China & Cerebrospinal fluid & HM366552 & HM366552 \\
\hline JEV/sw/Mie/41/2002 & । & 2002 & Mie, Japan & Swine serum & AB241119 & AB241119 \\
\hline K94P05 & 1 & 1994 & South Korea & C. tritaeniorhynchus & AF045551 & AF045551 \\
\hline XJP613 & I & 2007 & China & C. tritaeniorhynchus & EU693899 & EU693899 \\
\hline $\mathrm{FU}$ & $\|$ & 1995 & Australia & Human sreum & AF217620 & AF217620 \\
\hline SA14 & III & 1954 & China & Mosquito & U14163 & U14163 \\
\hline SA14-14-2 & III & IU & China & Vaccine & AF315119 & AF315119 \\
\hline P3 & III & 1949 & Beijing, China & Human brain & U47032 & U47032 \\
\hline Nakayama-RFVL & III & 1935 & Nakayama, Japan & Human brain & S75726 & \\
\hline GZ04-36 & III & 2004 & Guizhou, China & Culex & DQ404112 & \\
\hline HL02-134 & III & 2002 & Heilongjiang, China & Culicoides & DQ404081 & \\
\hline FJ03-31 & III & 2003 & Fujian, China & Human blood & DQ404117 & \\
\hline SH0601 & III & 2006 & Shanghai, China & Pig & EF543861 & EF543861 \\
\hline K87P39 & III & 1987 & Korea & Mosquito & AY585242 & AY585242 \\
\hline JaGAr01 & III & 1959 & Japan,Gunma & C. tritaeniorhynchus & AF039076 & AF039076 \\
\hline RP-9 & III & 1985 & Taiwan,China & Mosquito & AF14161 & AF14161 \\
\hline T1P1 & III & 1997 & Taiwan,China & Armigeres subalbatus & AF254453 & AF254453 \\
\hline Beijing-1 & III & 1949 & Beijing, China & Human brain & L48961 & L48961 \\
\hline Ling & III & 1965 & Taiwan,China & Mosquito & L78128 & L78128 \\
\hline P20778 & III & 1958 & India & Human brain & AF080251 & AF08251 \\
\hline JKT6468 & IV & 1981 & Indonesia,Flores & C. tritaeniorhynchus & AY184212 & AY184212 \\
\hline Muar & V & 1952 & Malaysia & Human brain & HM596272 & HM596272 \\
\hline XZ0934 & V & 2009 & China & Mosquito & JF915894 & JF915894 \\
\hline MVE & & 1951 & Australia & Human brain & NC_000943 & NC_000943 \\
\hline
\end{tabular}

"Isolated from the study 
17 to 22 August 2015, and consisted of six species from four genera (Table 3); Culex tritaeniorhynchus accounted for $73.08 \%$ (5 805/7 943), C. pipiens pallens for 24.75\% (1 966/7 943), and Anopheles sinensis, Aedes vexans, Ae. dorsalis, and Armigers subalbatus for about 3\% (104/7 943). C. tritaeniorhynchus was the dominant species in all counties, accounting for $70.81 \%$ (1 994/2 816), 77.03\% (2 505/3 252), and 69.65\% (1 306/1 875) of specimens from Linyi, Yongji, and Wangrong counties, respectively.

\section{Molecular identification of mosquito-borne viruses}

The mosquitoes were divided into 88 pools according to collection site, time, and species for homogenizing. RNA was extracted from $140 \mu \mathrm{l}$ aliquots of clarified homogenates. The viral RNA was used as the template for RTPCR using the seven mosquito-borne arbovirus primer sets listed in Table 1. The results are shown in Table 4. Among the 88 pools of mosquitoes, 16 were JEVpositive by RT-PCR amplification of the C/prM gene, among which 12 were C. tritaeniorhynchus and four were C. pipiens pallens. SXYC1546 and SXYC1548 specimens were JEV-positive by RT-PCR amplification of the JEV E gene. Sequence data for the E gene of SXYC1546 and SXYC1548 were deposited in GenBank. Among the 88 pools, 2 were positive for GETV using the $5^{\prime}$ UTR and NS1 gene primers. One SXYC1503 specimen (C. tritaeniorhynchus) was positive for both JEV and GETV at the same time. The collection site and mosquito species of positive specimens are listed in Table 4 .

\section{Virus isolation and identification}

The clarified homogenates that were positive for JEV and GETV were inoculated onto BHK-21cells at a constant temperature, and CPE was observed under an optical microscope every $8 \mathrm{~h}$. Among 17 pools of mosquitoes, only the SXYC1523 specimen isolated from C. pipiens pallens caused CPE in BHK-21 cells. Cells became round and shrank on day 3 after inoculation, CPE was up to $75 \%$ on day 4 , and a large number of cells detached from the wall of the Nunc tube (Fig. 2). No obvious $\mathrm{CPE}$ was observed in other pools compared to control cells.

Viral RNA was extracted from cell culture supernatant of SXYC1523 and RT-PCR was conducted with arbovirus gene primers. The cell supernatant was positive for JEV. Then 16 overlapping primers were used to amplify the complete open reading frame (ORF) of the SXYC1523 strain. The sequence of the ORF has been deposited in GenBank.

\section{MIR of JEV in mosquitoes}

Mosquito specimens were collected from the courtyards of eight farmers' households and two pig farms in Linyi, Yongji, and Wangrong counties. Of 45 pools of mosquito specimens from the courtyards of three farmers' households with pigsties (farmers A, B, and C) and two pig farms (pig farms A and B), 16 pools were positive for JEV in RT-PCR. The MIR of JEV from Culex, including C. tritaeniorhynchus and C. pipiens pallens, collected from three farmers' households with pigsties was 7.39/1 000, and that from Culex collected from the two pig farms was 2.68/1 000. Thus, the virus carrier rate of JEV in mosquito specimens collected from the courtyards of farmers' households with pigsties was as high or even higher than that from pig farms. Forty-three pools of mosquitoes collected from the courtyards of five farmers' households without pigsties were negative for JEV (Table 5).

\section{Molecular characterization of mosquito-borne viruses Phylogenetic analysis}

To understand the molecular genetic characteristics of the JEV isolates obtained in the present study, we selected 39 JEV strains covering genotypes I-V isolated from different countries and different species of mosquitoes from GenBank to establish phylogenetic trees based on the $E$ gene and ORF sequence together with the new isolates in this study. JEV was divided into five genotypes, and SXYC1523 isolated from C. pipiens pallens in

Table 3 Mosquitoes collected in Shanxi, China, 2015

\begin{tabular}{|c|c|c|c|c|c|c|c|c|}
\hline \multirow[t]{3}{*}{ Mosquito species } & \multicolumn{6}{|c|}{ Collection sites } & \multirow{2}{*}{\multicolumn{2}{|c|}{ Total }} \\
\hline & \multicolumn{2}{|l|}{ Linyi } & \multicolumn{2}{|l|}{ Yongji } & \multicolumn{2}{|c|}{ Wanrong } & & \\
\hline & No. & $\%$ & No. & $\%$ & No. & $\%$ & No. & $\%$ \\
\hline Culex tritaeniorhynchus & 1994 & 70.81 & 2505 & 77.03 & 1306 & 69.65 & 5805 & 73.08 \\
\hline C. pipiens pallens & 765 & 27.17 & 704 & 21.65 & 497 & 26.51 & 1966 & 24.75 \\
\hline Anopheles sinensis & 57 & 2.02 & 3 & 0.09 & 44 & 2.35 & 104 & 1.31 \\
\hline Aedes vexans & 0 & 0 & 35 & 1.08 & 0 & 0 & 35 & 0.44 \\
\hline Aedes dorsalis & 0 & 0 & 5 & 0.15 & 0 & 0 & 5 & 0.06 \\
\hline Armigers subalbatus & 0 & 0 & 0 & 0 & 28 & 1.49 & 28 & 0.35 \\
\hline Total & 2816 & 100 & 3252 & 100 & 1875 & 100 & 7943 & 100 \\
\hline
\end{tabular}


Table 4 Specimens positive for mosquito-borne virus genes in Shanxi, China, 2015 by RT-PCR amplifications

\begin{tabular}{|c|c|c|c|c|}
\hline Collection site & Mosquito species & Sample title & viruses & No. Of each pool \\
\hline The courtyards of farmer A' households with pigsties & Culex tritaeniorhynchus & SXYC1537 & JEV & 100 \\
\hline \multirow[t]{3}{*}{ The courtyards of farmer $B^{\prime}$ households with pigsties } & C. tritaeniorhynchus & SXYC1503 & JEV/GETV & 75 \\
\hline & C. pipiens pallens & SXYC1523 & JEV & 20 \\
\hline & C. tritaeniorhynchus & SXYC1527 & JEV & 48 \\
\hline \multirow[t]{2}{*}{ Pig farm A } & C. tritaeniorhynchus & SXYC1542 & JEV & 100 \\
\hline & C. tritaeniorhynchus & SXYC1562 & JEV & 100 \\
\hline \multirow[t]{7}{*}{ Pig farm B } & C. pipiens pallens & SXYC1530 & JEV & 100 \\
\hline & C. tritaeniorhynchus & SXYC1546 & JEV & 100 \\
\hline & C. tritaeniorhynchus & SXYC1548 & JEV & 100 \\
\hline & C. tritaeniorhynchus & SXYC1549 & JEV & 100 \\
\hline & C. tritaeniorhynchus & SXYC1551 & GETV & 100 \\
\hline & C. tritaeniorhynchus & SXYC1553 & JEV & 100 \\
\hline & C. tritaeniorhynchus & SXYC1555 & JEV & 100 \\
\hline \multirow[t]{4}{*}{ The courtyards of farmer $C^{\prime}$ households with pigsties } & C. tritaeniorhynchus & SXYC1570 & JEV & 100 \\
\hline & C. tritaeniorhynchus & SXYC1582 & JEV & 100 \\
\hline & C. pipiens pallens & SXYC1586 & JEV & 100 \\
\hline & C. pipiens pallens & SXYC1588 & JEV & 100 \\
\hline
\end{tabular}

avirus isolation obtained

1. Mosquitoes were collected from eight courtyards of farmers' households (three with pigsties and five without pigsties) and two pig farms

2. The 16 pools of mosquito specimens positive for JEV were collected from the courtyards of three farmers' households with pigsties (farmers A, B, and C) and

two pig farms (pig farms $A$ and $B$ )

Shanxi was located in the branch of genotype I (Fig. 3a). In phylogenetic analyses based on the E gene (Fig. 3b), SXYC1523, SXYC1546, and SXYC1548 derived from mosquitoes in Shanxi Province in 2015 were all located in the branch of genotype I.

\section{JEV identity and variation in amino acid sequences}

The levels of nucleotide and amino acid sequence identity of the JEV E gene were $99.5-100 \%$ and $100 \%$, respectively, in three strains (SXYC1523, SXYC1546, SXYC1548). Comparison of the nucleotide and amino acid sequences of the E gene between SXYC1523 strain and 39 other strains used in phylogenetic analyses indicated a nucleotide identity ranging from $72.8 \%$ (XZ0934) to $98.7 \%$ (XJ69) and an amino acid identity ranging from 90.6\% (XZ0934) to $100 \%$. The nucleotide sequence identity of the E gene between SXYC1523 with genotype I JEV ranged from $96.3 \%$ (Ishikawa) to $98.7 \%$ (XJ69), and the amino acid sequence identity ranged from $98 \%$ (Ishikawa) to $100 \%$. Amino acid sequence identity of the $\mathrm{E}$ protein between the SXYC1523 strain and local JE strains (12YJ033, 12-LY039, 12-TJ022) isolated in 2012 was $100 \%$.

The E protein is a major structural protein of JEV and is closely related to viral virulence. To analyze the key amino acids, we compared the E protein of strains isolated in this study (SXYC1523, SXYC1546, SXYC1548) to SA14-14-2, an attenuated vaccine strain, and other virulent strains (Table 6). The results suggested that eight key amino acid residues were not different in these three strains derived from mosquitoes collected in the areas with a high incidence of adult JE in this study, compared to JEV strains isolated from mosquitoes,

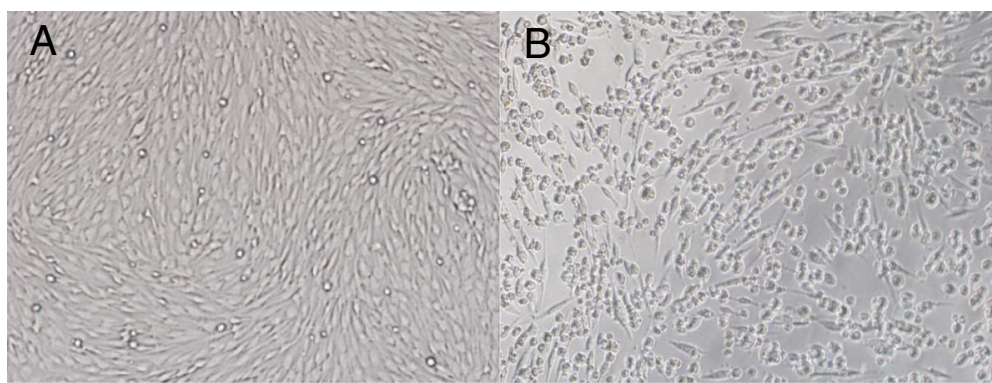

Fig. 2 Phase-contrast photomicrographs of control and infected BHK-21 cells. a Control cells. b Cells 4 days after infection with SXYC1523 
Table 5 Minimum infection rate (MIR) of JEV in mosquitoes in this study

\begin{tabular}{|c|c|c|c|c|c|}
\hline Collection sites & Mosquito species & No. Individuals & No.pools & No. Positive Pools & $\begin{array}{l}\text { MIR } \\
\text { (/1000 }\end{array}$ \\
\hline \multirow[t]{3}{*}{ The courtyards of farmers' households with pigsties ${ }^{\mathrm{a}}$} & Culex tritaeniorhynchus & 723 & 8 & 5 & 6.92 \\
\hline & C. pipiens pallens & 360 & 5 & 3 & 8.3 \\
\hline & Subtotal & 1083 & 13 & 8 & 7.39 \\
\hline \multirow[t]{3}{*}{ Pig farm ${ }^{b}$} & C.tritaeniorhynchus & 2433 & 26 & 7 & 2.88 \\
\hline & C. pipiens pallens & 552 & 6 & 1 & 1.81 \\
\hline & Subtotal & 2985 & 32 & 8 & 2.68 \\
\hline \multirow[t]{3}{*}{ The courtyards of farmers' households without pigsties ${ }^{c}$} & C. tritaeniorhynchus & 2649 & 33 & 0 & 0 \\
\hline & C. pipiens pallens & 1054 & 10 & 0 & 0 \\
\hline & Subtotal & 3703 & 43 & 0 & 0 \\
\hline
\end{tabular}

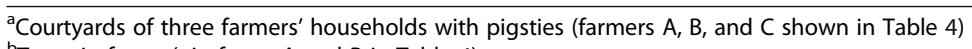

${ }^{\mathrm{b}}$ Two pig farms (pig farms A and B in Table 4)

'Courtyards of five farmers' households without pigsties

porcine serum, or specimens from patients with encephalitis, regardless of genotype. These results suggest that the virulence of JEV circulating in these regions in 2015 has not changed.

\section{Discussion}

JE is mainly endemic to Asia [1, 2, 4]. The scope of JE prevalence, however, has been gradually expanding in recent years, and JE has already spread to northwest Australia and Guam in the Pacific region, where it has become an emerging arboviral disease [17-19]. JEV is a mosquito-borne virus, and mosquitoes belonging to various genera, such as Culex, Anopheles, Armigeres, and Aedes, can all transmit it. Among these species, Culex, in particular C. tritaeniorhynchus, is the most important vector $[19,20]$. The larvae of C. tritaeniorhynchus prefer to

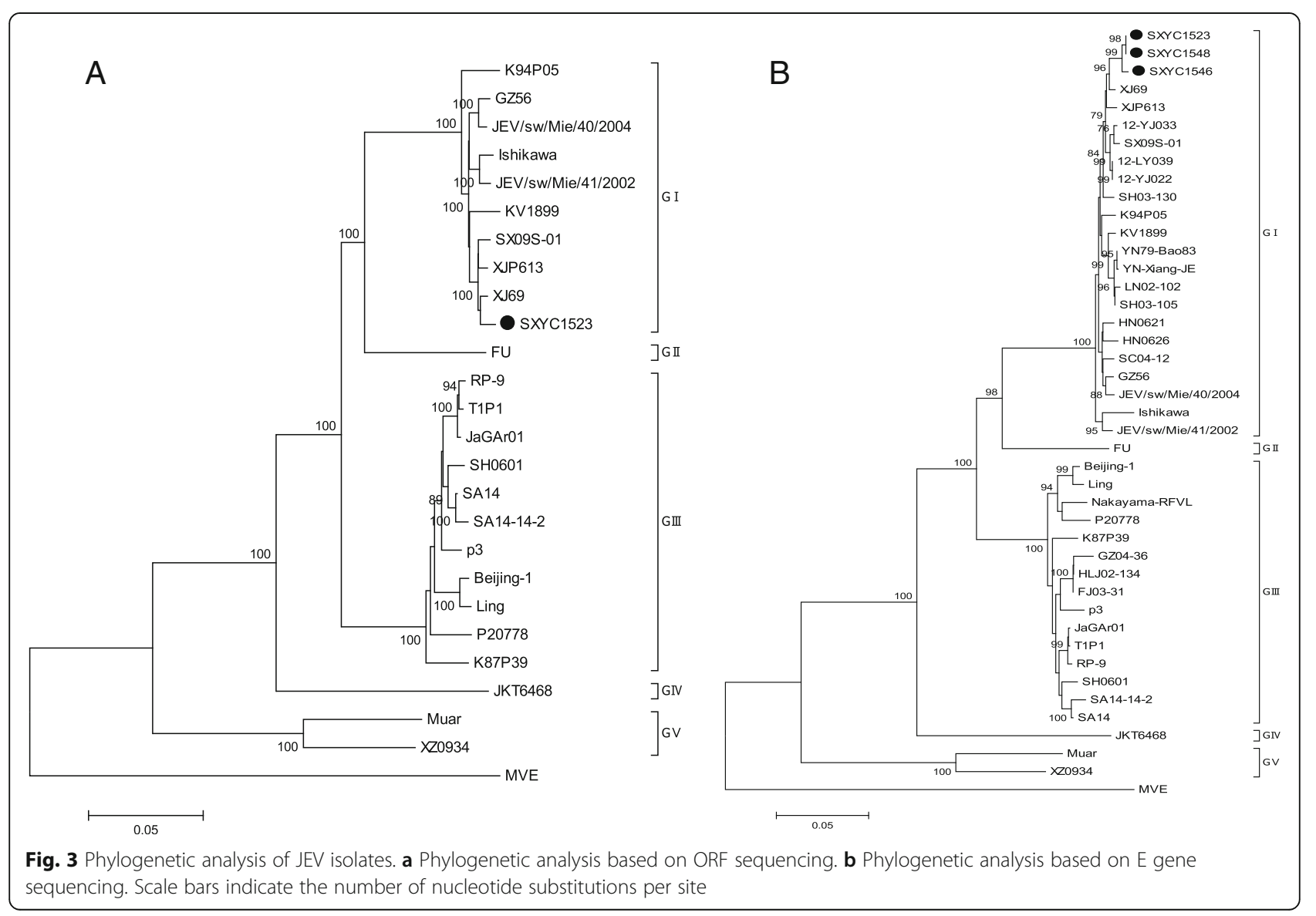


Table 6 Comparison of key amino acid residues of the E protein related to neurovirulence of JEV ${ }^{\mathrm{a}}$

\begin{tabular}{|c|c|c|c|c|c|c|c|c|}
\hline Strain & E107 & E138 & E176 & E177 & E264 & E279 & E315 & E439 \\
\hline SA-14-14-2 (GIII) & Phe(F) & Lys(K) & $\operatorname{Val}(\mathrm{V})$ & $\mathrm{Ala}(\mathrm{A})$ & $\mathrm{His}(\mathrm{H})$ & $\operatorname{Met}(\mathrm{M})$ & $\operatorname{Val}(\mathrm{V})$ & $\operatorname{Arg}(R)$ \\
\hline $\operatorname{SXYC1523^{b}(GI)}$ & Leu(L) & Glu(E) & $\| e(l)$ & $\operatorname{Thr}(\mathrm{T})$ & $\mathrm{G} \ln (\mathrm{Q})$ & $\operatorname{Lys}(K)$ & $\mathrm{Ala}(\mathrm{A})$ & Lys $(K)$ \\
\hline SXYC1546 ${ }^{\mathrm{b}}(\mathrm{Gl})$ & Leu(L) & $\mathrm{Glu}(\mathrm{E})$ & $\| e(l)$ & $\operatorname{Thr}(\mathrm{T})$ & $\mathrm{G} \ln (\mathrm{Q})$ & $\operatorname{Lys}(K)$ & $\operatorname{Ala}(A)$ & Lys $(K)$ \\
\hline 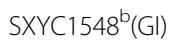 & $\operatorname{Leu}(\mathrm{L})$ & $\mathrm{Glu}(\mathrm{E})$ & $\| e(l)$ & $\operatorname{Thr}(\mathrm{T})$ & $\mathrm{G} \ln (\mathrm{Q})$ & $\operatorname{Lys}(K)$ & $\operatorname{Ala}(\mathrm{A})$ & $\operatorname{Lys}(K)$ \\
\hline SX09S-01(GI) & Leu(L) & $\mathrm{Glu}(\mathrm{E})$ & lle(l) & $\operatorname{Thr}(T)$ & $\mathrm{G} \ln (\mathrm{Q})$ & Lys(K) & $\mathrm{Ala}(\mathrm{A})$ & $\operatorname{Lys}(K)$ \\
\hline 12-YJ033(GI) & Leu(L) & Glu(E) & $\| e(l)$ & $\operatorname{Thr}(\mathrm{T})$ & $\mathrm{G} \ln (\mathrm{Q})$ & $\operatorname{Lys}(K)$ & $\mathrm{Ala}(\mathrm{A})$ & $\operatorname{Lys}(K)$ \\
\hline GZ56(Gl) & Leu(L) & $\mathrm{Glu}(\mathrm{E})$ & $\| e(l)$ & $\operatorname{Thr}(T)$ & $\mathrm{G} \ln (\mathrm{Q})$ & Lys $(K)$ & $\operatorname{Ala}(A)$ & Lys $(K)$ \\
\hline $\mathrm{FU}(\mathrm{GII})$ & Leu(L) & $\mathrm{Glu}(\mathrm{E})$ & $\| \mathrm{l}(\mathrm{l})$ & $\operatorname{Thr}(T)$ & $\mathrm{G} \ln (\mathrm{Q})$ & Lys(K) & $\mathrm{Ala}(\mathrm{A})$ & $\operatorname{Lys}(K)$ \\
\hline Nakayama(GIII) & Leu(L) & $\mathrm{Glu}(\mathrm{E})$ & \|le(l) & $\operatorname{Thr}(\mathrm{T})$ & $\mathrm{G} \ln (\mathrm{Q})$ & Lys(K) & $\mathrm{Ala}(\mathrm{A})$ & Lys(K) \\
\hline P3 (GIII) & Leu(L) & $\mathrm{Glu}(\mathrm{E})$ & Ile(l) & $\operatorname{Thr}(\mathrm{T})$ & $\mathrm{G} \ln (\mathrm{Q})$ & Lys(K) & $\mathrm{Ala}(\mathrm{A})$ & $\operatorname{Lys}(K)$ \\
\hline JKT6468(GIV) & Leu(L) & $\mathrm{Glu}(\mathrm{E})$ & $\| \mathrm{ll}(\mathrm{l})$ & $\operatorname{Thr}(\mathrm{T})$ & $\mathrm{G} \ln (\mathrm{Q})$ & Lys $(K)$ & $\mathrm{Ala}(\mathrm{A})$ & $\operatorname{Lys}(K)$ \\
\hline Muar(GV) & Leu(L) & $\mathrm{Glu}(\mathrm{E})$ & lle(l) & $\operatorname{Thr}(\mathrm{T})$ & $\mathrm{G} \ln (\mathrm{Q})$ & Lys(K) & Ala(A) & $\operatorname{Lys}(K)$ \\
\hline XZ0934(GV) & Leu(L) & Glu(E) & $\| \mathrm{l}(\mathrm{l})$ & $\operatorname{Thr}(T)$ & $\mathrm{G} \ln (\mathrm{Q})$ & Lys(K) & $\mathrm{Ala}(\mathrm{A})$ & Lys(K) \\
\hline
\end{tabular}

${ }^{a}$ These eight aa residues of the E protein were shown to play a key role in neurovirulence. They are very different between the attenuated vaccine strain (SA14-14-2) and the virulent strains

${ }^{\mathrm{b}}$ Isolated in Shanxi, 2015 in this study

propagate in clean water, such as the water in rice fields, while the larvae of $C$. pipiens pallens generally propagate in sewage and the adults inhabit human dwellings. Therefore, it is easy for mosquitoes to propagate in rural areas with rich water resources, poor sanitation, and sewage $[19,20]$. Pigs become infected with JEV via mosquito bites, and the virus is greatly amplified in pigs. This makes pigs, including both domestic and feral pigs, amplification hosts for local endemic JEV [19-21]. The infected pigs may also be hosts for further spread of JEV by mosquito bites. Therefore, a short distance between dwelling places and pigsties or the habitats of feral pigs will increase the probability of exposure to JEV. Populations living in environments with high mosquito density and surrounded by pigsties will be prone to JEV infection [22].

Our results suggest that the dominant mosquito specie in Linyi, Yongji, and Wanrong counties of Shanxi Province is still C. tritaeniorhynchus, and the endemic JEVs belong to genotype I, consistent with most parts of China and Asia [23]. The eight key amino acid residues determining the virulence of JEV isolates in this study have not changed compared to previous strains and local strains isolated in 2012, suggesting that local endemic JEV shows high neurovirulence [24]. These results suggest that the dominant mosquito species, genotypes, and virulence of JEV have not changed in Linyi, Yongji, and Wanrong, where the incidence of adult JE has been continuously high. Hence, these regions are still natural endemic foci of JEV with persist risk of infection.

In this study, we collected mosquito specimens from the courtyards of eight farmers' households and two pig farms. There were pigsties in the courtyards of three farmers' households but not in those of the other five households. Five to ten pigs were raised in the pigsties in the courtyards, and these pigsties were close to human houses. In addition, chickens, ducks, geese, and other domestic animals were also raised in the courtyards at the same time. Therefore, there was a great deal of stagnant water polluted by the feces of various animals in the living environment, which provided an appropriate environment for mosquitoes to propagate. Eight of thirteen pools of mosquito specimens collected from the courtyards of the above three farmers' households with pigsties were positive for JEV based on RTPCR amplification of the C/PrM gene, and the MIR was $7.39 / 1000$, higher than that $(2.68 / 1000)$ of mosquitoes collected from pig farms (Table 5). For the other five courtyards of the farmers' households without pigsties, their pigs were all raised in pig farms far away from villages (over 2-5 km). Although large numbers of $C$. tritaeniorhynchus and $C$. pipiens pallens were present in the above five courtyards, JEV was not detected from these mosquitoes. Therefore, it is clear that whether the mosquitoes carried JEV was directly related to the location of pigsties in the courtyards (Table 5). The transmission cycle of JEV was blocked due to the lack of amplification hosts in the above five courtyards without pigsties. In contrast, the presence of pigs in the other three courtyards with pigsties completed the circle of JEV transmission as mosquito (virus)-pig-mosquito (virus), which made JEV more active and resulted in large numbers of mosquitoes carrying the virus. This concept is supported by another example from South Korea. During 2010-2015, South Korea reported 129 JE cases, some of which lived close to pigsties [7]. In 
conclusion, the presence of pigsties close to human dwellings provides an amplification host for JEV, which leads to JEV proliferation in local areas and increases the risk of human infection with JEV.

\section{Conclusion}

A JE vaccine was included in the EPI in 2008 in China, and children can be inoculated with it free of charge; it has greatly reduced the incidence of JE cases among children in China $[9,22]$. Adults were not inoculated with this vaccine in childhood (long before the implementation of EPI) and therefore are more susceptible to JEV infection [10]. In addition, the habit of farmers to raise pigs in their own courtyards increases the risk of infection with JEV. Therefore, in regions with high prevalence rates of adult JE, such as Linyi, Yongji, and Wanrong, it is necessary to implement JE vaccination and strengthen the management of local animal husbandry. Pigs should be raised intensively in pig farms far from human dwellings with implementation of modern management. Farmers should cease the practice of raising pigs in their own courtyards to reduce the risk of infection with JEV and further decrease the incidence of adult JE.

\section{Additional file}

Additional file 1: Multilingual abstracts in the six official working languages of the United Nations. (PDF $633 \mathrm{~kb}$ )

\section{Abbreviations}

BHK-21: Baby hamster kidney cell line; CPE: Cytopathic effect; DMEM: Dulbecco's Modified Eagle's Medium; EPI: The national Expanded Program of Immunization; FBS: Fetal bovine serum; GETV: Getah virus; JE: Japanese encephalitis; JEV: Japanese encephalitis virus; MIR: Minimum infection rate; MVE: Murray Valley encephalitis virus.; NJ: Neighbor-joining; ORF: Open reading frame; RT-PCR: Reverse transcription-polymerase chain reaction

\section{Acknowledgements}

We thank the staff of the Shanxi Center for Disease Control and Prevention for assistance with collection of mosquito samples. We also thank the National Natural Science Foundation of China for financially supporting this research.

\section{Funding}

This work was supported by grants from National Natural Science Foundation of China (81290342 and 81501757), and Development Grant of State Key Laboratory of Infectious Disease Prevention and Control (2014SKLID103). The funders had no role in study design, data collection and analysis, decision to publish, or preparation of the manuscript.

\section{Availability of data and materials}

The sequence of JEV strains in this study has been deposited in GenBank. The JE data used in this study were obtained from the China Information System for Diseases Control and Prevention (available at http:// www.phsciencedata.cn/Share/index.jsp).

\section{Authors' contributions}

$X R$, SF, PD contributed equally to this work. They collected the mosquitoes, did the experiments and wrote the manuscript. HW conceived and guided the experiment. $X L$ and $X G$ made the picture and performed the data analysis. YL, WL, YH and ZL did some experiments. JC collected the mosquitoes. GW and GL participated in the whole process and modified the manuscript. All authors read and approved the final manuscript.

\section{Competing interests}

The authors declare that they have no competing interests.

\section{Consent for publication}

Not applicable.

\section{Ethics approval and consent to participate}

The study did not use patient's medical records and all data were analyzed anonymously.

\section{Author details}

'Department of Immunology and Microbiology, Shanxi Medical University, Taiyuan 030001, China. ${ }^{2}$ State Key Laboratory of Infectious Disease Prevention and Control, National Institute for Viral Disease Control and Prevention, Chinese Center for Disease Control and Prevention, Beijing 102206, China. ${ }^{3}$ Collaborative Innovation Center for Diagnosis and Treatment of Infectious Diseases, Hangzhou 310058, China. ${ }^{4}$ Shanxi Center for Disease Control and Prevention, Taiyuan 030001, China.

Received: 4 November 2016 Accepted: 28 April 2017

Published online: 08 June 2017

\section{References}

1. Lindenbach BD, Thiel HJ, Rice CM. Flavivirdae :the viruses and their replication. In: Knipe DM, Howley PM, editors. Wolter KluwerLippincott Willian\&Wikins. 5th ed. Philadephia: Academic; 2007. p. 1102-53.

2. Halstead SB, Jacobson J. Japanese encephalitis vaccines. In: Plotkin SA, Orenstein WA, Offit PA, editors. Vaccines. 5th ed. Philadelphia: Elsevier; 2008. p. 311-52.

3. Erlanger TE, Weiss S, Keiser J, Utzinger J, Wiedenmayer K. Past, present, and future of Japanese encephalitis. Emerg Infect Dis. 2009;15(1):1-7.

4. Campbell GL, Hills SL, Fischer M, Jacobson JA, Hoke CH, Hombach JM, Marfin AA, Solomon T, Tsai TF, Tsu VD, Ginsburg AS. Estimated global incidence of Japanese encephalitis: a systematic review. Bull World Health Organ. 2011;89(10):766-74. doi:10.2471/BLT.10.085233. 774A-774E.

5. Wang LH, Fu SH, Wang HY, Liang XF. Japanese encephalitis outbreak,Yuncheng,China. Emerg Infec Dis. 2007;13(7):1123-5.

6. Vashishtha VM, Ramachandran VG. Vaccination policy for Japanese encephalitis in India: Tread with caution! Indian Pediatr. 2015;52(10):837-9.

7. Gao XY, Nasci R, Liang GD. The neglected arboviral infections in mainland China. PLoS Negl Trop Dis. 2010;4(4):e624. doi:10.1371/journal.pntd.0000624.

8. Gao XY, Li XL, Li MH, Fu SH, Wang HY, Lv Z, et al. Vaccine Strategies for the Control and Prevention of Japanese Encephalitis in Mainland China, 19512011. PLoS Negl Trop Dis. 2014;8(8):e3015. doi:10.1371/journal.pntd.0003015.

9. Zheng YY, Li MH, Wang HY, Liang GD. Japanese encephalitis and Japanese encephalitis virus in mainland China. Rev Med Virol. 2012;22:301-22.

10. Li X, Cui S, Gao X, Wang H, Song M, Li M, et al. The Spatio-temporal Distribution of Japanese Encephalitis Cases in Different Age Groups in Mainland China, 2004-2014. PLoS Negl Trop Dis. 2016;10(4):e0004611. doi: 10.1371/journal.pntd.0004611.

11. Wang J, Zhang H, Sun $X$, Fu S, Wang H, Feng $Y$, Wang $H$, Tang $Q$, Liang GD. Distribution of mosquitoes and mosquito-borne arboviruses in Yunnan Province near the China-Myanmar-Laos border. Am J Trop Med Hyg. 2011; 84(5):738-46.

12. Sun X, Fu S, Gong Z, Ge J, Meng W, Feng Y, Wang J, Zhai Y, Wang H, Nasci $\mathrm{R}$, Wang $H$, Tang Q, Liang G. Distribution of arboviruses and mosquitoes in northwestern Yunnan Province, China. Vector Borne Zoonotic Dis. 2009;9(6): 623-30.

13. Kuno G, Mitchell CJ, Chang GJ, Smith GC. Detecting bunyaviruses of the Bunyamwera and California serogroups by a PCR technique. J Clin Microbiol. 1996;34(5):1184-8.

14. Lv X, Mohd Jaafar F, Sun $X$, et al. Isolates of Liao Ning Virus from WildCaught Mosquitoes in the Xinjiang Province of China in 2005. PLoS One. 2012;7(5):e37732. doi:10.1371/journal.pone.0037732.

15. Zhai YG, Wang HY, Sun XH, Fu SH, Wang HQ, Attoui H. Complete sequence characterization of isolates of Getah virus (genus Alphavirus, family Togaviridae) from China. J Gen Virol. 2008;89(Pt 6):1446-56. doi:10.1099/vir.0. 83607-0. 
16. Feng Y, Fu S, Zhang H, Li M, Zhou T, Wang J, Zhang Y, Wang H, Tang Q, Liang G. Distribution of mosquitoes and mosquito-borne viruses along the ChinaMyanmar border in Yunnan Province. Jpn J Infect Dis. 2012;65(3):215-21.

17. Mackenzie JS, Gubler DJ, Petersen LR. Emerging flaviviruses: the spread and re- surgence of Japanese encephalitis, WestNile and dengue viruses. Nat Med. 2004;10(12 Suppl):S98-S109.

18. Weaver SC, Reisen WK. Present and future arboviral threats. Antiviral Res. 2010:85:328-45.

19. Mackenzie JS, Williams DT, Smith DW. Japanese encephalitis virus: the geographic distribution, incidence, and spread of a virus with a propensity to emerge in new areas. In: Tabor E, editor. Emerging Virusin Human Populations. Amsterdam: Elsevier BV; 2007. p. 201-68.

20. van den Hurk AF, Ritchie SA, Mackenzie JS. Ecology and geographical expansion of Japanese encephalitis virus. Annu Rev Entomol. 2009;54:17-35. doi:10.1146/annurev.ento.54.110807.090510.

21. Le Flohic G, Porphyre V, Barbazan P, Gonzalez JP. Review of climate, landscape, and viral geneticsas drivers of the Japanese encephalitis virus ecology. PLoS Negl Trop Dis. 2013;7(9):e2208. doi:10.1371/journal.pntd. 0002208.

22. Solomon T. Control of Japanese encephalitis - within our grasp? N Engl J Med. 2006;355(9):869-71.

23. Pan XL, Liu H, Wang HY, Fu SH, Liu HZ, Zhang HL, Li MH, Gao XY, Wang JL, Sun XH, Lu XJ, Zhai YG, Meng WS, He Y, Wang HQ, Han N, Wei B, Wu YG, Feng Y, Yang DJ, Wang LH, Tang Q, Xia G, Kurane I, Rayner S, Liang GD. Emergence of genotype I of Japanese encephalitis virus as the dominant genotype in Asia. J Virol. 2011:85(19):9847-53.

24. Zheng Y, Cao Y, Fu S, Cheng J, Zhao J, Dai P, Kong X, Liang G. Isolation and identification of mosquito-borne arboviruses in Yuncheng City, Shanxi Province, 2012. Chin J Epidemiol. 2015;36(4):368-73 (in Chinese).

\section{Submit your next manuscript to BioMed Central and we will help you at every step:}

- We accept pre-submission inquiries

- Our selector tool helps you to find the most relevant journal

- We provide round the clock customer support

- Convenient online submission

- Thorough peer review

- Inclusion in PubMed and all major indexing services

- Maximum visibility for your research

Submit your manuscript at www.biomedcentral.com/submit
Biomed Central 